conference Dr. Stock from Stoke was able to produce the plans of the North Staffordshire Institute which commenced building later that year. Planning had started in 1959 , an appeal for funds was launched in 1960, and it was thus the first centre of its kind, not only to be built, but to be conceived and planned.

To pay tribute to the foresight of Stoke is in no way to diminish the vast importance of the Christ Church conference, and the support of the Nuffield and the King's Fund. Not to do so, however, is to permit the establishment by default of false history, and the creation of a perpetual injustice. I make this point in the sense of historical accuracy and with the vicarious pride of an honorary member of the section of general practice in the North Staffordshire Medical Institute.I am, etc.,

P. S. BYRNE

Manchester

\section{Influence of pH on Radioimmunoassay of} Angiotensin I

SIR,-It has been demonstrated by Pickens and coworkers ${ }^{1}$ that a $\mathrm{pH}$ of 5.5 is critical for the reaction of human renin with human renin substrate. While studying the radioimmunoassay of angiotensin I we observed that the plasma $\mathrm{pH}$ varied from physiological levels to $\mathrm{pH} 8$ according to the length of time of storage of the plasma. We then tried to evaluate the variation in angiotensin I values in a pool of plasma obtained from 110 subjects for hypertensive hormone assay, according to the usual technique, ${ }^{2}$ with the addition of enzymatic blockers. From this plasma pool we prepared 10 aliquots of $15 \mathrm{ml}$ each and with $\mathrm{pH}$ values of from 4.5 to 9 , increasing in steps of 0.5 . The activity of plasma renin was maximum at $\mathrm{pH} 6$, while a striking decrease of activity was observed at $\mathrm{pH}$ 7-8.

It seems as if the curves of hormone formation at each $\mathrm{pH}$ value are the linear function of the incubation time. The curves of angiotesnin I formation in relation to $\mathrm{pH}$ values show a gaussian distribution, the highest slope being $\mathrm{pH} 6$. Therefore to avoid mistakes during the assay of angiotensin I we suggest that the plasma should be at the optimum $\mathrm{pH} 6$. In this way the highest hormone production is obtained, and when plasma renin activity is low hormone values are easier to measure.-We are, etc.,

B. BAGNI R. SQUERZANTI A. FARINELLI

Servizio di Nefrologia, Istituto di Radiologia, Arcispedale S. Anna,

Ferrara, Italy 1 Pickens, $\mathbf{P} . \mathbf{T}_{\text {Smeby, }} \mathbf{R}_{\mathbf{R}}$ Bumpus, F. M. Land Page, I. Loyd, A. M., Research, 1965, 17, 438.

2 Bagni, B., Gilli, P., Imbimbo, G. C., Squerzanti, R., and Farinelli,

\section{Brodrick Report}

SIR,-A recent leading article (15 July, p. 131) implies that if the Brodrick Committee's proposals (20 November 1971, p. 498) are accepted then coroners' postmortem examirations will be provided free under the National Health Service. While certainly recommending that they should be provided under the N.H.S., I can find no mention in the report that they should be provided free.

The majority of pathologists are of the opinion that the coroners' service should be independent. This opinion is held for legal and ethical reasons-to avoid conflicts of interest and loyalty. One should not give the impression that the Brodrick recommendation is opposed for financial reasons. Actually it would be to the pathologists' advantage if they were paid by the N.H.S. as then this remuneration would count for their pensions. - I am, etc.,

Department of Pathology,

Burnley

G. BEHR

\section{Sulphonamide Crystalluria with} Acetazolamide

SIR,-Acetazolamide is a heterocyclic sulphonamide and a carbonic anhydrase inhibitor. It used to be used as a mild diuretic. Since more effective diuretics are now available the drug is mainly used for the treatment of glaucoma; its sulphonamide basis tends to be forgotten. In the following case anuria renal colic, and uraemia, considered to be due to sulphonamide crystalluria, resulted from administration of this drug.

A 49-year-old man was treated with acetazolamide $250 \mathrm{mg}$ three times daily for glaucoma secondary to iritis. After seven doses he de veloped nausea, vomiting, and bilateral renal colic. On admission to hospital he was apyrexial, his blood pressure was $150 / 95 \mathrm{~mm} \mathrm{Hg}$, pulse rate 98 , and he had some bilateral loin tenderness. Acetazolamide therapy was discontinued He became anuric and catheterization produced $10 \mathrm{ml}$ of heavily blood-stained urine. O microscopy only erythrocytes and leucocytes were seen. Culture was sterile.

The blood urea after 24 hours was $144 \mathrm{mg} /$ $100 \mathrm{ml}$ and it rose to $258 \mathrm{mg} / 100 \mathrm{ml}$ the day after. The serum potassium also rose from 4.4 $\mathrm{mEq} / 1$. to $6 \mathrm{mEq} / 1$. Intravenous pyelography with $80 \mathrm{ml}$ of Conray 420 showed on a six hour film widening of the collecting system, including the ureters, with no contrast in the bladder, suggesting lower ureteric obstruction Ureteric catheterization three days after ad mission showed bilateral lower ureteric blocks with cellular debris. No calculi were seen. Only the left ureter could be cleared by flushing with saline. Subsequently the patient was treated with sodium bicarbonate $4 \mathrm{~g}$ and 3 litres of oral fluid daily. A good diuresis was obtained, and the blood urea fell to $38 \mathrm{mg} / 100$ $\mathrm{ml}$ within four days. Repeat intravenous pyelography a week after admission showed ormal excretion.

Sulphonamide crystalluria has been reported previously with acetazolamide therapy of four to nine days duration.1-4 Only seven $250 \mathrm{mg}$ doses of acetazolamide were given to our patient. This rare but grave complication should be remembered because of it rapid response to therapy. -We are, etc.,

R. T. Orchard

D. J. E. TAYLOR Charing Cross Hospital,

R. A. Parkins 1 Glushien, A. S., and Fisher, E. R., foumal of 2 Yates-Bell, J. G., British Medical foumal, 1958, Davies, D. W., British Medical fournal, 1959, Bertino, J. R., Rodman, T., and Myerson, R. M.,

\section{Ergocryptine}

SIR,-In our article (24 June, p. 743) on the suppression of puerperal lactation with an ergot alkaloid 2-Br-alpha-ergocryptine was referred to throughout as "egocryptine." To avoid any confusion we would like to state that ergocryptine is a natural alkaloid existing in two isometric forms (aipha and beta) which both differ markedly in their pharmacological profiles and being both different from the pharmacological profile of 2-Br-alpha-ergocryptine. It is therefore misleading to use ergocryptine as a sort of generic name for 2-Br-alpha-ergocryptine.I am, etc.

Norfolk and Norwich Hospital.
Norfolk

J. S. Pryor

\section{Cot Deaths and Hypokalaemia}

SIR,-It would be interesting to speculate on whether some unexpected cot deaths may be the result of an acute hypokalaemia and could be averted by the simple addition of potassium supplem.nts in infant feeding.

A situation might easily develop where a baby sweating profusely in a warm room with a mild unnoticed pyrexia could suffer rapid electrolyte changes with potassium depletion and sudden death, and of course postmortem examination would not give any explanation for the tragedy. I submit this suggestion in all humility, fully appreciating the massive work which has been done on this subject.-I am, etc.,

J. A. Frais

Shipley, Yorks

\section{Diagnosis of Sarcoidosis by Labial Gland Biopsy}

SIR,-The article by Drs. G. R. V. Hughes and N. J. Gross (22 July, p. 215) prompted the biopsy of a labial salivary gland at the same time as a parotid biopsy in a 50-yearold woman with bilateral parotid gland enlargement who had a chest $x$-ray strongly suggestive of sarcoidosis. The labial biopsy showed a minor salivary gland, the histology of which was normal. The biopsy of the accessory part of one parotid gland, however, showed non-caseating tubercles typical of sarcoidosis. The tuberculin skin test was negative at 1 in 1,000 . The Kveim reaction has not yet been done.

Drs. Hughes and Gross suggest that pathological changes in the minor salivary glands of the lip reflect those of the major salivary glands, though Waterhouse and Doniach, 1 whom they quote, do not mention this. This may well be the case, but the finding of a histologically normal labial gland does not exclude sarcoidosis in the major salivary glands. I wish to thank Mr. R. V. Fiddian for permission to refer to this case.-I am, etc.

Luton and Dunstable Hospital,

T. BATES

Luton LU4 0DZ

1 Waterhouse, J. P., and Doniach, I., Yournal of

Malathion-resistant Pediculosis Capitis

SIR.-The resistance of the pediculus to DDT and to gammexane has been well reported. I have to report my first case of 